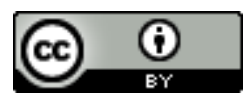

\title{
A AVALIAÇÃO "É A BOLA GIRANDO NA RODA" REFLEXÕES SOBRE PRÁTICAS AVALIATIVAS NA UNIVERSIDADE
}

\begin{tabular}{c}
\hline THE EVALUATION “IS THE BALL TURNING ON THE WHEEL” \\
REFLECTIONS ON EVALUATION PRACTICES AT UNIVERSITY \\
LA EVALUACIÓN "ES LA BOLA GIRANDO EN LA RUEDA" \\
REFLEXIONES SOBRE PRÁCTICAS EVALUADAS EN LA UNIVERSIDAD \\
\hline
\end{tabular}

\author{
Fabrício Oliveira da Silva ${ }^{1}$ \\ Marinalva Lopes Ribeiro ${ }^{2}$ \\ Lucile Ruth de Menezes Almeida ${ }^{3}$
}

\begin{abstract}
RESUMO: O trabalho analisa como a pesquisa ação-colaborativa se constitui em um espaço de diálogo e reflexão sobre práticas educativas e avaliativas na universidade. Trata-se de uma dinâmica de pesquisa desenvolvida com docentes de diversas áreas de uma universidade pública do estado da Bahia, que regularmente discutem suas práticas pedagógicas nos contextos de ensino em que atuam. Para este artigo, analisamos as reflexões que faz uma professora do Departamento de Exatas da universidade, com o objetivo de compreender como a docente se insere num processo autoavaliativo por meio do qual revela e (re)significa suas práticas educativas e avaliativas no contexto do ensino de Química. Como dispositivo metodológico, utilizamos narrativas da docente produzidas em forma de relatos orais durante um encontro do grupo de pesquisa. Os resultados do estudo evidenciam que, inicialmente, a docente concebe a avaliação da aprendizagem como um processo voltado para aferição, cuja preocupação é com a existência de uma nota como reflexo da aprendizagem. A partilha, a troca de experiências e a autoavaliação sobre as práticas na docência universitária promovem reflexões que reverberam outros modos de compreensão e de desenvolvimento do fazer docente na universidade.
\end{abstract}

PALAVRAS-CHAVE: Autoavaliação. Avaliação formativa. Pesquisa-ação colaborativa.

ABSTRACT: The paper analyzes how action-collaborative research constitutes a space for dialogue and reflection on educational and evaluative practices in the university. It is a research dynamic developed with teachers from several areas of a public university in the state of Bahia, who regularly discuss their pedagogical practices in the contexts of teaching in which they work. For this article, we analyze the reflections made by a professor at the University 's Department of Exact, in order to understand how the teacher is inserted in a self - assessment movement through which she reveals and (re) means her educational and evaluative practices in the teaching context of chemistry. As a methodological device, we used teacher narratives produced in the form of oral reports during a research group meeting. The results of the study show that, initially, the teacher conceives the evaluation of learning as a verification process, whose concern is the existence of a note as a reflection of learning. The sharing, exchange of experiences and self-assessment about practices in university teaching promote reflections that reverberate other ways of understanding and developing teaching at the university.

KEYWORDS: Self-assessment. Formative avaluation. Collaborative research-action.

RESUMEN: El trabajo analiza cómo la investigación acción-colaborativa se constituye en un espacio de diálogo y reflexión sobre prácticas educativas y evaluativas en la universidad. Se trata de una dinámica de investigación desarrollada con docentes de diversas áreas de una universidad pública del estado de Bahía, que regularmente discuten sus prácticas pedagógicas en los contextos de enseñanza en que actúan. Para este artículo, analizamos las reflexiones que hace una profesora del Departamento de Exactas de la universidad, con el objetivo de comprender cómo la docente se inserta en un movimiento autoevaluatorio por medio del cual revela y (re)

Submetido em: 05/05/2018 - Aceito em: 02/07/2018 - Publicado em: 11/07/2018.

\begin{tabular}{l|l|l|l|l|l}
\hline (C) Rev. Inter. Educ. Sup. & Campinas, SP & v.4 & n.3 & p.664-684 & set./dez. 2018 \\
\hline
\end{tabular}


significa sus prácticas educativas y evaluativas en el contexto de la enseñanza de química. Como dispositivo metodológico, utilizamos narrativas de la docente producidas en forma de relatos orales durante un encuentro del grupo de investigación. Los resultados del estudio evidencian que, inicialmente, la docente concibe la evaluación del aprendizaje como un proceso orientado a la evaluación, cuya preocupación es con la existencia de una nota como reflejo del aprendizaje. El compartir, el intercambio de experiencias y la autoevaluación sobre las prácticas en la docencia universitaria promueven reflexiones que reverberan otros modos de comprensión y de desarrollo del hacer docente en la universidad.

PALABRAS CLAVE: Autoevaluación. Evaluación formativa. Investigación-acción colaborativa.

\section{INTRODUÇÃO}

O objetivo deste estudo é o de compreender como os professores participantes de uma pesquisa-ação colaborativa desenvolvem suas práticas educativas e como no processo dialógico, reflexivo e auto-avaliativo com os pares produzem inovações nas interações em sala de aula e, consequentemente nos diferentes modos de avaliar as aprendizagens. Como recorte para a discussão neste artigo, analisamos a narrativa de uma professora participante da pesquisa, com o objetivo de compreender como ela, na reflexão com os pares sobre sua docência na universidade, vai revelando perspectivas de práticas avaliativas e educativas que desenvolve no ensino de Química.

A discussão que aqui se produz leva em conta a identificação dos paradigmas sobre avaliação da aprendizagem que se evidenciam nos relatos frutos das rodas de conversa que a docente produziu em alguns momentos da pesquisa-ação. Trata-se, portanto, das experiências com a prática avaliativa que a docente desenvolve na universidade e que partilha com os demais docentes participantes da pesquisa-ação colaborativa.

A pesquisa-ação colaborativa, no seu terceiro ano de desenvolvimento, conta com 14 professores de duas universidades, além de 4 estudantes da pós-graduação, 4 bolsistas de Iniciação Científica e alguns voluntários. Como descrito no seu projeto (RIBEIRO e MUSSI, 2015, p.10), trata-se de um "desenho de pesquisa que envolve os próprios docentes enquanto sujeitos pesquisados e pesquisadores das suas próprias práticas pedagógicas, a fim de que possam transformá-las em práticas inovadoras”. De acordo com Pimenta (2005, p.06),

[...] a práxis pedagógica dos professores envolvidos na pesquisa, partindo da própria ação docente, refletida, fundamentada teoricamente e sistematizada se constitui uma modalidade de formação contínua com amplas possibilidades transformadoras e emancipatórias.

Dentre seus objetivos, a pesquisa que originou este trabalho apresenta:

Identificar as problemáticas que envolvem as práticas pedagógicas dos docentes universitários; Buscar colaborativamente suporte entre os pares e nos referenciais teóricos para superar as problemáticas que envolvem as práticas pedagógicas dos 
docentes universitários, para enfrentá-las de forma inovadora. (RIBEIRO e MUSSI, 2015, p.11).

Estabelecemos, na referida pesquisa-ação colaborativa, alguns instrumentos para a coleta e produção dos dados, como: o grupo focal, a entrevista, a gravação em vídeo de aulas dos professores e os relatos destes sujeitos em rodas de conversas que acontecem a cada 15 dias, durante 2 horas, na sala do núcleo de pesquisa.

O relato é caracterizado pela descrição pessoal, por parte dos docentes, de episódios marcantes, experiências vividas, sensações e sentimentos ligados à sua prática pedagógica, mediante os quais poderemos apreender informações sobre a realidade da sala de aula do professor universitário, narradas pelos protagonistas. (RIBEIRO e MUSSI, 2015, p.20).

Na pesquisa-ação colaborativa, construída por um grupo de professores de diferentes áreas do conhecimento, criou-se um ambiente de aprendizagem fértil para que o processo de autoavaliação de cada um esteja ativa numa troca constante, socializando dificuldades encontrando, assim, encaminhamentos e soluções processuais. Começamos a ver como resultados que alguns participantes começam a teorizar o que fazem e integrar a base teórica pedagógica de forma que uma consciência crítica das mudanças vai sendo construída. Neste contexto a avaliação como um elemento das ações humanas e necessariamente também acadêmicas começa a usar a dinâmica da autoavaliação como propulsora de construção cognitiva teoricamente fundamentada, em outras palavras, permitindo compreender a dinâmica da prática docente com base na concepção de aprendizagem construtivista do paradigma emergente.

Para este trabalho, tomamos os dados produzidos em uma das rodas de conversa, na qual filtramos os sentidos e modos de entender e praticar a avaliação nas práticas educativas que uma professora faz na universidade. Buscamos entender, quais os paradigmas sobre a avaliação que se fazem presentes nas ações educativas desenvolvidas pela docente colaboradora, Com o objetivo de entender, quais os paradigmas que fundamentam as concepções de aprendizagem e sua prática avaliativa que se fazer presentes nas ações educativas desenvolvidas pela docente colaboradora, buscamos estabelecer um diálogo entre os resultados encontrados com os paradigmas que orientam as práticas avaliativas na educação superior.

Entender, propor e gerenciar a avaliação da aprendizagem levando em consideração a sua complexidade tem se colocado como um desafio que professores universitários se lançam na tentativa de transpor a prática de avaliação enquanto verificação da aprendizagem. Avaliar na concepção de aprendizagem construtivista do paradigma emergente pressupõe uma construção dialógica entre diferentes sujeitos - professor e aluno - que envolve um paradigma que se assenta na ideia de construção de processos cognitivos que põem em evidência a ação reflexiva de construção de saberes, logo, de desenvolvimento de 
aprendizagens. Neste contexto, a avaliação se apresenta como uma dinâmica mobilizadora de entendimento da ação reflexiva que o sujeito faz em torno de si mesmo, do outro e do mundo que o cerca, com vistas a construir mecanismos de produção e análise sobre a aprendizagem. Essa perspectiva de entendimento parte do pressuposto de que a avaliação é um elemento essencial nas ações humanas, é um processo que permite gerenciar a relação consigo e com o outro, tem como princípio elucidativo no conhecimento e reflexão de si e de sua prática que o professor desenvolve quando se lança na ideia de que avaliar pressupõe, em primeira instância, avaliar a si mesmo e os modos como desenvolve a ação avaliativa na sua prática. Neste contexto, a avaliação tem estreita relação com os processos metacognitivos que geram a autoavaliação do sujeito, momento em que este se coloca na posição reflexiva de entender a si mesmo e aos seus propósitos na ação educativa que desenvolve na universidade.

Na prática universitária, os professores têm lançado mão de estratégias de ensino que tenham como princípio fundante o desenvolvimento e efetivação da aprendizagem dos estudantes. É sob a condição de favorecer formas dinâmicas e exequíveis de aquisição do conhecimento, que os professores recorrem a ações educativas, e sobre elas refletem na perspectiva de entendê-las em sua essência formativa para os estudantes. Nessa busca, é que a avaliação em sua função formativa emerge como uma dinâmica complexa, que objetiva favorecer a funcionalidade, tanto das práticas educativas dos professores, como dos resultados cognitivos revelados pelos estudantes. Nesta direção, ao buscar movimentar-se no sentido de entender a legitimidade de suas práticas e do processo de avaliação de que lança mão, o professor muitas vezes se insere na perspectiva autoavaliativa, que segundo Hadji (2001, p. 102), deve concentrar-se na efetivação de um autobalanço, tentando fazer a autoregulação mais favorável à melhoria "[...] do sistema interno de orientação para aumentar a eficiência da autorregulação [...].”.

A autorregulação desencadeia um modo de compreensão particular que o professor desenvolve em busca de pôr-se na centralidade do processo avaliativo, por meio do qual busca desenvolver reflexões sobre como avalia e a partir de quais motivações. Geralmente, é a tentativa de garantir que os alunos tomem consciência de que é preciso aprender o que os docentes ensinam e que avaliação se presentifica na prática educativa como algo necessário para aferir se a aprendizagem acontece ou não.

Isso implica considerar que a avaliação da aprendizagem e do ensino tem estreita relação com os processos autoavaliativos que o professor desenvolve de si, considerando os modos de ensinar e desenvolver estratégias de ensino que favoreçam as aprendizagens. Essa condição de mobilizar-se a pensar sobre si e sobre como age quando ensina e quando avalia exige um processo de gestão metacognitiva, o qual considera os procedimentos que o professor realiza no seio de sua atividade educativa, balizada sempre por um processo reflexivo que considera o saber como elemento ativo na produção de estratégias avaliativas de que lança mão o docente, sobretudo porque se trata de um modo de entendimento autorregulativo como forma 
de entender a eficácia das atividades educativas, dentre as quais a avaliação, que o professor desenvolve na universidade (POZO; ECHEVERRÍA 2009).

A prática educativa e sua proposta de prática avaliativa teoricamente fundamentada ou ingênua se estruturam num modelo epistemológico e propõe um cotidiano de sala de aula que gerencia as ações dos sujeitos do processo de ensino e aprendizagem. Quando vão acontecendo mudanças nesta prática provoca uma necessidade de ajustes da mesma. De início pode acontecer ingenuamente, mas o processo de mudanças vai exigindo do docente respostas para ajustar a realidade. A prática avaliativa pode ser um entrave para mudanças definitivas, pois os alunos desde o início do processo indagam o docente sobre como vão ser avaliados. Eles têm experiências anteriores que começam a ser desestabilizadas. Propor e vivenciar mudanças não é algo fácil. É invadir o novo que ainda não promete que será eficiente.

Todavia, como sugere Behrens (2003, p. 27):

A crise e a resistência fazem parte deste processo de transposição: por um lado provocam um mal-estar na comunidade científica, derrubando alguns pilares de sustentação dos pensamentos, conceitos e ações, e por outro, instiga cientistas e intelectuais para reverem suas teorias e buscarem uma profunda renovação de suas concepções [...] a superação de um paradigma científico não o invalida, não o torna errado ou nulo, mas evidencia que seus pressupostos e determinantes não correspondem mais às novas exigências históricas. A passagem para um novo paradigma não é abrupta e nem radical. É um processo que vai crescendo, se construindo e se legitimando. Na realidade, o novo paradigma incorpora alguns referenciais significativos do velho paradigma e que ainda atendem aos anseios históricos da época. Nesse processo de transição, os cientistas passam a desafiar os pressupostos do velho paradigma embora ao anunciar um mundo novo ainda se assentem em bases mais utópicas do que concretas [...] a formação de um novo paradigma ocorre nas entranhas do anterior. E este, por sua vez, nunca desaparecerá totalmente.

\section{PARADIGMAS NA CIÊNCIA E SUA INFLUÊNCIA NA PRÁtICA EDUCATIVA}

Antes de iniciarmos a nossa reflexão sobre os paradigmas da ciência, analisando as principais correntes epistemológicas que apresentam repercussões nas práticas educativas até a atualidade, consideramos interessante esclarecer aos leitores o conceito de paradigma que defendemos.

Neste texto, o conceito de paradigma é entendido como o concebe Edgar Morin (2004), para quem existe uma noção nuclear linguística, lógica e ideológica básica que determina o curso de todas as teorias e discursos. Morin (2004) emprega paradigma como um tipo de relação muito forte, que controla todos os discursos, inclusive a lógica desses discursos, de modo que obedecemos, mesmo sem saber, a esse paradigma, com poder de separação, de conjunção, de simplificação, de legislação soberana. Nesse sentido, o paradigma, além de controlar as teorias, controla, ao mesmo tempo, a organização técnico burocrática da sociedade.

\begin{tabular}{l|l|l|l|l|l} 
(C) Rev. Inter. Educ. Sup. & Campinas, SP & v.4 & n.3 & p.664-684 & set./dez. 2018 \\
\hline
\end{tabular}


Contudo, Morin, ao defender a epistemologia complexa, se contrapõe à existência do que chama "Senhor epistemológico", que controla de modo irredutível e irremediável todo o saber, defendendo uma pluralidade de instâncias, cada uma comportando incertezas, portanto incapaz de ser verdadeira ou falsa. Em suas próprias palavras:

Dicho de otro modo: incluso las condiciones más singulares, las más localizadas, las más particulares, las más históricas de la emergencia de una idea, de una teoría, no son prueba de su veracidad -claro está- ni tampoco de su falsedad. Dicho de otro modo, hay un principio de incertidumbre en el fondo de la verdad. Es el problema de la epistemología; es el problema de la dialéctica; es el problema de la verdade. (MORIN,2004, p. 19)

A partir dessa lógica, Lima e Grillo (2008) afirmam que, mesmo que não esteja claro para o professor, o modo como desenvolve a docência, está amparado por concepções explícitas ou implícitas sobre o conhecimento, o professor e o aluno. Destarte, Behrens (2003, p. 14) apresenta a organização histórica do processo pedagógico dizendo que existem duas dimensões:

\begin{abstract}
Uma dimensão assentada no paradigma newtoniano-cartesiano, que caracterizou um ensino fragmentado e conservador, que tem como foco central a reprodução do conhecimento. [...] A outra dimensão, caracterizada como inovador, tem como eixo central a produção do conhecimento. Designada como paradigma emergente, tem-se baseado na visão holística, propondo uma ciência que supere a fragmentação em busca do todo e que contemple as conexões, o contexto e as inter-relações dos sistemas que integram o planeta. $O$ desafio significativo nesta passagem paradigmática é a tentativa de aproximação do sujeito e do objeto, num processo que recupera a emoção e a intuição aliada à razão. Ao investigar os pressupostos e tendências inovadoras, apresenta-se a proposição de uma metodologia alicerçada por um projeto pedagógico do professor que busque a produção do conhecimento dos alunos e do professor [...] com a preocupação de se formar um cidadão sensível, intuitivo, feliz, e que seja competente para contribuir na reconstrução da sociedade.
\end{abstract}

$\mathrm{Na}$ perspectiva de uma prática voltada para a produção do conhecimento, como visto anteriormente no excerto de Behrens, a prática docente precisa estar alinhada ao momento histórico em que vivemos, chamado "sociedade do conhecimento", marcado por profundas transformações nos processos produtivos, sociais, econômicos e políticos. Assim, para acompanhar tais mudanças, Carpim; Behrens; Torres (2014, p. 5) defendem que a prática educativa, fundada no paradigma da complexidade, também chamado de emergente, holístico e inovador, precisa levar em consideração "um ensino dialógico que promova uma ação educativa dinâmica e não fragmentada, por meio da estruturação de um currículo que una ética, ciência e sociedade" no qual os docentes proponham atividades educativas em que os estudantes relacionem, com criticidade, os conhecimentos teóricos com a prática. Nesse sentido, a partir de uma visão crítica, criativa e transformadora, a prática educativa pode superar a forma mecanizada e linear que marca o paradigma tradicional, cuja prática, como vimos anteriormente, era mecanizada e linear. 
Entretanto, a autora apresenta que "a passagem para um novo paradigma não é abrupta e nem radical. É um processo que vai crescendo, se construindo e se legitimando" (BEHRENS, 2003, p. 27). Partindo desses pressupostos, podemos compreender como e porque as mudanças processuais vão acontecendo, pois quando as ações geradas num paradigma começam a não solucionar mais situações que ele deve gerenciar então se começa a procurar maneiras de organizar mudanças que tragam melhoria e proporcionem o alcance dos objetivos almejados.

A existência do paradigma da ciência moderna (cartesiano-newtoniano) que controla o saber e a nossa visão de realidade tem gerado uma crise no meio educacional, considerando, como afirma Moraes (1997), que ensina os estudantes a não questionar, a não expressar o pensamento divergente, a ter certeza das coisas e a aceitar a autoridade de forma passiva, o que pode trazer consequências prejudiciais para a formação de novas gerações.

Embora a universidade continue influenciada por uma sistemática de exames em que "as provas assumem um papel central determinando o comportamento do aluno, privilegiando a memória e a capacidade de expressar o que foi acumulado"(MORAES, 1997, p. 52), percebemos, no processo de desenvolvimento da pesquisa-ação colaborativa, algumas experiências que tentam se afastar de tal modelo fechado, fragmentado e autoritário. Quando o professor comprometido com sua prática docente começa a encontrar problemas de aprendizagem na sua disciplina ele começa a tentar alternativas com o objetivo de encontrar soluções mais satisfatórias que possam contribuir para minimizar a reprovação, repetência e desmotivação dos alunos. Nesse processo vão encontrando algumas respostas isoladas e na maioria das vezes sem uma fundamentação teórica dessas mudanças. É neste contexto de busca que ele começa a sua jornada como um docente reflexivo de sua própria docência. É um processo de autoavaliação da própria prática. Momentos de reflexão para encontrar respostas aos problemas que vivencia.

Na tentativa de pensar em como auxiliar os seus alunos em um componente curricular que considera difícil, a professora Angélica ${ }^{2}$ busca produzir uma reflexão sobre sua ação educativa, que encontra lugar e significados no momento em que na roda de conversa ela desvela uma preocupação com a aprendizagem dos alunos, razão que a mobiliza a criar uma condição propositiva de ajuda aos seus alunos. Neste sentido, é a própria prática e a avaliação que faz desta o elemento mobilizador da autoavaliação e da reflexão partilhada com o coletivo na roda de conversa que a professora revela a construção de um paradigma educativo que se consolida nos modos de pensar essa docência para garantir a aprendizagem de seus alunos. Em um trecho de seus relatos, a professora assim nos diz:

\footnotetext{
${ }^{2}$ Em atendimento ao que preconiza o Comitê de Ética em pesquisas que envolvem humanos, utilizamos nomes fictícios com objetivo de preservar a identidade dos colaboradores do estudo. 
A 409 é uma disciplina problemática de Química. Ao fazer a proposta da primeira unidade eu fiz a seguinte mudança: os alunos chegam com, além das deficiências de Química, não sabem estudar. Eu me propus a ver se eu consigo ajudá-los a modificar o formato com que eles estudam. (Angélica, relato da roda de conversa 2017)

A professora começa a se preocupar com o desenvolvimento de habilidades de estudo dos estudantes. O relato evidencia uma atitude da professora de empreender esforços em querer analisar o modo como os discentes estudam a fim de promover modificações, no que ela denomina de formato do estudo, por acreditar que os estudantes não o fazem de modo apropriado aos contextos de uma disciplina que entende ser problemática. A avaliação é transversal na prática da professora, que a utiliza a serviço da aprendizagem de seus alunos ao propor uma mudança que visa (re)organizar os caminhos que estes percorrem para conseguirem aprendizagem em Química. Isso implica numa dimensão da docente de conceber a avaliação enquanto processo e não apenas como coleta de dados para verificação da aprendizagem e nota. $\mathrm{O}$ que se pretende atingir com a mudança proposta pela docente é fruto de um processo avaliativo que se origina na perspectiva pedagógica, que como defende Luckesi (1995) torna-se útil e necessária para que professores e educandos busquem a melhor construção de si mesmos e consequentemente o melhor modo de ser na vida, logo na universidade e na aprendizagem de Química.

É na tentativa de criar uma condição de prática educativa e de avaliação, que a professora Angélica desenvolve um processo reflexivo que considera, conforme preconiza Behrens ( 2003), passa-se de um processo a outro de forma processual, visto que as mudanças de paradigmas são construídas histórica e coletivamente. No entanto, é importante ressaltar que no movimento da pesquisa-ação colaborativa o diálogo com os pares favorece a explicitação dos processos colaborativos de cada um que emergem dos modos próprios de pensar e de favorecer uma mudança de paradigmas. Neste contexto, as indagações que o professor faz a si mesmo reverberam no coletivo e voltam para que ele mesmo encontre sentidos e ações nas mudanças que propõe para alcançar novos resultados. Isso implica no reconhecimento de que os docentes participantes vão desvelando sentidos e modos de fazer a aula e a avaliação acontecer na universidade, para as quais a preocupação torna-se um elemento que favorece a autoavaliação que o professor faz de si, gerando um contexto que prima por busca de entendimento de seus modos de fazer, ainda que neles seja possível evidenciar um paradigma mais cartesiano de aprendizagem e de prática educativa. Nesse movimento reflexivo, em outro trecho de sua ponderação na roda de conversa, a professora Angélica considera que

E se a gente não se preocupar? Antes o DEXA (Departamento de Ciências Exatas) oferecia duas turmas: a turma dos calouros e a turma dos repetentes. Me leva a pensar que a gente precisa mudar de alguma forma. O que é importante: dar a minha contribuição aqui. A minha proposta é esta: Pelo menos pra primeira unidade. Já tenho algumas ideias para a segunda unidade. Mas não estão tão bem elaboradas. (Angélica, relato da roda de conversa 2017) 
Ao afirmar que o importante é dar sua contribuição, a professora mostra preocupar-se com a aprendizagem dos estudantes, levando em consideração os contextos de elevado índice de repetência e de desistência. Fica, contudo, explicito que Angélica tem uma representação do estudante e que trabalha com tal representação. Ela ainda não consegue desvestir-se do papel tradicional da professora autoritária, ainda não consegue flexibilizar: ela dá as regras. Regras que autoritariamente ela impõe, e que não são construídas pelo coletivo. Isso tem a ver com as representações que a professora tem construído ao longo de sua trajetória na universidade. Ela traz à baila situações com as quais viveu na docência universitária, como ter distintas turmas de química ofertada pelo DEXA. É evidente a preocupação em apropriar-se de estratégias do fazer docente na universidade que gerem aprendizagens e que permitam aos alunos a permanência no curso. A ênfase na importância e na necessidade do domínio da Química por parte dos estudantes é tomada como motivação para fazer a prática educativa acontecer de modo diferente, mesclada pela preocupação com a permanência dos estudantes no curso. A mudança de atitude figura como um paradigma de consciência de si e do fazer docente, que revela os processos de reflexividade que a professora passa a construir sobre seus modos de ensinar e consequentemente de avaliar seus alunos. A isso se soma a instauração de uma concepção de que é por meio da avaliação na sua função formativa e não apenas usando a verificação classificatória, que o aluno revela e constrói aprendizagens em Química.

Apesar de se evidenciar um paradigma cartesiano da avaliação, que a concebe como classificação e como instrumento de poder, a professora Angélica desenvolve um processo autoavaliativo, em que o conhecimento de si e o reconhecimento de suas dificuldades e do modo autoritário de desenvolvimento de práticas educativas a faz produzir uma reflexividade que a move querer, ainda que não saiba como, promover mudanças em seus paradigmas avaliativos, frente ao ensino de Química na universidade.

Quando ela no diz: Eu me acho muito contundente, muito incisiva, muito autoritária. Eu não sei se eu mudar isso, eu perder isso, eu não perco o caminho. Eu acho que o grupo tem muito o que me ajudar, consegue autoavaliar-se. Reconhece o seu autoritarismo. Este é um momento de reflexão fundamental, nas palavras de Almeida (2011, p. 82), "de encontro com as suas verdades, o seu conhecimento e a realidade, caracterizada então pela sua prática com um determinado grupo de alunos." É importante notar que tais autoavaliações servem para reorientar o processo de ensino e aprendizagem. O reconhecimento e a percepção de que a sua forma de agir na docência é contundente e autoritária sugere que a professora toma consciência dessas caracterizações e busca produzir sentidos que ela mesma reconhece não serem pertinentes e adequados para atingir resultados esperados. Nesse processo reflexivo, e por estar inserida num grupo de docentes universitários, busca partilhar suas dificuldades como modo de tornar-se compreendida pelos pares e a partir disso receber ajuda para que possa instaurar outros modos de fazer sua docência, sobretudo no que tange à avaliação que faz de si mesma e de seus alunos. Isso não é fácil e demanda que o professor esteja sensível 
ao diálogo e à construção de motivações que se iniciam no reconhecimento de dificuldades e limitações que enfrenta. Esta é a condição que a professora se coloca, de estar em reconhecimento de suas dificuldades, mas propensa a construir novos caminhos em sua trajetória profissional com o apoio dos colegas participantes da pesquisa.

O reconhecimento da professora Angélica sobre sua atitude contundente frente ao ato de avaliar, bem como da necessidade de ajuda dos colegas professores que participam da pesquisa-ação colaborativa encontra respaldo num paradigma de formação cujo foco foi sempre a racionalidade. Do elogio da razão e da crítica da emoção. Aprendemos a pensar com a cabeça e não com o coração.

Entendemos e defendemos, portanto, que a avaliação enquanto processo constitutivo de organização e reorganização dos caminhos que se trilha para promover aprendizagens na universidade, transcende a mera noção de aferição do conhecimento, pois tem estreita relação com os modos de ensinar e de aprender que o professor gesta na sala de aula, produzindo um conjunto de ações na sua prática educativa, que considera o ato de avaliar como transversal da prática. Nessa dimensão, o processo avaliativo se constitui na dinâmica organizacional das teorias implícitas (POZO; ECHEVERRÍA 2009) que congrega os valores e princípios da reflexão na ação de fazer e de aplicar tarefas escolares. Neste contexto, a racionalidade tem dado espaço aos modos operativos do pensar, também emotivamente. O homem não é mais um sujeito da razão, agora está propenso, também, a ser sujeito da emoção. Reconhece-se contundente, incisivo, mas também um sujeito que precisa de ajuda, que sente medo de errar caso mude o caminho, mas que reconhece a necessidade de mudar para inaugurar não só uma nova forma de avaliar os estudantes, mas, sobretudo, de desenvolver práticas educativas que sejam emancipatórias e que permitam aos discentes aprenderem.

Esse cenário reflexivo abre espaço para que na sua prática a professora Angélica crie condições para o diálogo, por meio do qual passa a escutar os estudantes, se aproximando deles. Isso implica no reconhecimento de estabelecimento de ponderações que ela passa a usar como forma de retratar um ambiente dialógico com esses sujeitos. Num trecho em que relata uma de suas práticas avaliativas, a professora assim representa o diálogo que teve com seus estudantes numa aula de Química:

$\mathrm{O}$ que eu estou fazendo aqui hoje? Eu estava discutindo a resposta que uma aluna havia me dado. Aí perguntei novamente: o que foi que você falou? A gente vai percebendo que a resposta que a aluna deu foi de grupo. Teve de tudo nessa aula, todos falaram. Esse foi o acordo inicial. O acordo inicial foi isso que eles (os alunos) teriam que falar, que me dizer: o que eu quero neste momento? Discutir a estrutura atômica até orientá-los. Porque está muito ligada à física. (Angélica, relato da roda de conversa 2017).

Aqui a professora mostra uma possibilidade de avaliar a aprendizagem de outra forma, com o uso de outro instrumento. Ela avalia pelas respostas e participação dos sujeitos, considerando 
que o coletivo, o grupo de estudantes deve ser considerado. Quando uma estudante fala, fala pelo grupo e isso passa a significar que Angélica se preocupa não com a perspectiva de um sujeito apenas, mas com o que o conjunto dos alunos refletem e sugerem. A perspectiva dialógica inaugura na prática da professora um modo de entendimento de aprendizagem e sua avaliação que vai passando para outro estágio, consolidando-se de modo mais flexível, tendo em vista que o seu objetivo maior é que eles aprendam sobre a estrutura atômica e possa disso fazer uso. Nestas condições, vemos uma perspectiva de pensar a avaliação como um processo, assim como a aprendizagem é. A oralidade entra como umas das possibilidades de se construir caminhos formativos, em que a aprendizagem da Química seja uma realidade mais motivacional para os estudantes, logo para a professora também.

A professora experimenta novas estratégias de aprendizagem para que os estudantes expressem o que aprenderam. Como afirma Pozo (2009, p. 200), o professor é entendido

Como um sujeito estratégico que toma decisões a partir de suas teorias e crenças antes, durante e depois da interação com os alunos. O conteúdo das ideias dos docentes se converte assim na prioridade de estudo para a compreensão e melhoria da atividade em aula.

Ao buscar ancorar os seus modos avaliativos numa perspectiva dialógica com seus estudantes, a professora vai constituindo suas aulas numa dinâmica mais flexível, por meio da qual as estratégias passam a figurar em seu repertório e em suas crenças sobre formas de aprender que sejam mais funcionais, tendo em vista os contextos em que desenvolve suas aulas. Neste sentido, a professora lança mão de um processo avaliativo marcado pelos atos interrelacionais com os estudantes. É o diálogo, a convivência, a observação, a leitura da realidade e necessidade dos estudantes elementos que passam a ser considerados pela professora a fim de desenvolver aprendizagem destes na química. A isso se agregam aos valores e ideias que tem a docente para fazer sua aula acontecer numa ancoragem das representações que constrói para si sobre a melhor maneira de conseguir resultados em suas aulas. A esse respeito, a professora se vê motivada a conseguir seus objetivos educativos, razão pela qual ela vai mudando de atitude a partir das relações que estabelece com seus alunos, antes, durante e após o desenvolvimento de cada atividade.

Em outro trecho de seu relato, ela foca a prática educativa no processo avaliativo dizendo que

O objetivo não é nota. $O$ objetivo é a bola girando na roda. É a discussão. E o professor mediador do processo de aprendizagem. Por que eu preciso dar esta regra? Porque ela é vital para que a coisa aconteça. Se eu coloco nesta linguagem, com alunos do começo do semestre, o que acontece? As linguagens precisam ser diferentes. (Angélica, relato da roda de conversa 2017)

Notamos, pela narrativa de Angélica, o quanto a professora deseja mudar a sistemática da avaliação da aprendizagem. Ela objetiva a avaliação como: é a bola girando na roda. Todavia, existe uma contradição em sua perspectiva. Se o objetivo não é a nota, como a 
professora expressou anteriormente que A prova vale 4, o trabalho de laboratório vale 4. Uma vez corrigido eu faço uma série de perguntas. Eu divido a turma em trios. Eu faço uma prova oral por que ela insiste tanto em focar nos instrumentos, prova oral, trabalho de laboratório, prova escrita? Talvez, e cremos ser a melhor explicação, isso tem a ver com a ideia de que as notas reveladas pelos instrumentos avaliativos sejam indicativos de que a aprendizagem aconteceu a contento. Ainda é possível pensar na possibilidade de que o foco na nota e nos instrumentos esteja relacionado à motivação dos estudantes na universidade, que em alguns contextos, está voltada mais para a conquista de uma boa nota do que para a aprendizagem. É comum vermos situações avaliativas em que o grande objetivo do estudante é tirar uma boa nota e a aprendizagem estaria como consequência disso. Se se tirou uma boa nota, é sinal que aprendeu o conteúdo. Essa concepção ainda está bastante presente nos contextos avaliativos da universidade, na polarização discursiva tanto de estudantes, como de professores. No caso de Angélica, vemos uma flutuação nas perspectivas avaliativas, que ela transita em diferentes modos de compreensão. Ora revelando preocupações com a aprendizagem da Química, com a apreensão e produção do conhecimento por parte dos estudantes, ora ela preocupando-se com os instrumentos avaliativos e com os resultados que os estudantes devem alcançar neles. Por isso a ênfase nos instrumentos e nos pesos de cada avaliação, mas sem desconsiderar que no contexto de sua prática avaliativa a aprendizagem esteja desejada e presente. Contudo, está sempre implícita a ideia de regulação da aprendizagem que parece se efetivar na autoridade do professor e na sua condição de planejar, elaborar, aplicar e validar os instrumentos de avaliação.

Almeida (2011) nos ajuda a compreender tal situação. Analisando a perspectiva reflexiva de Angélica em sua narrativa, fica explicito que as notas servem para mostrar ao estudante a sua posição na escala hierárquica de excelência, no lugar de ajudá-lo a compreender o que aprendeu, seus avanços, dificuldades, o que ainda falta para aprender, isto é, identificar os conhecimentos construídos e os modos de raciocínio de cada estudante para que pudesse auxiliá-lo a progredir no alcance dos objetivos (ALMEIDA, 2011, p. 85).

Neste sentido, a avaliação é vista como instrumento de regulação contínua da ação pedagógica, a fim de o professor conhecer os obstáculos encontrados pelos estudantes no processo de aprendizagem. E essa visão perturba e faz o professor ter a falsa sensação de que a avaliação em que acredita valora a aprendizagem. De fato, a aprendizagem dos alunos é objeto da motivação da professora, que busca no seu jeito autoritário de ser conseguir que seus alunos aprendam. A métrica da aprendizagem neste contexto é a nota. E a regulação significa tirar uma boa nota. Se os alunos não tiram ou não se dedicam para estudar, como devem, surge a estratégia de intimidar e elevar a pontuação como forma de atrair os estudantes para a responsabilidade com o estudo. Essa atitude, ao que vemos no relato da professora, pouco tem contribuído para a aprendizagem dos discentes, mas a tem motivado perceber que o objetivo maior é a aprendizagem de seus alunos e que para conseguir isso, terá que conceber uma avaliação para além da simples noção de aferição da aprendizagem.

\begin{tabular}{l|l|l|l|l|l|} 
(C) Rev. Inter. Educ. Sup. & Campinas, SP & v.4 & n.3 & p.664-684 & set./dez. 2018 \\
\hline
\end{tabular}




\section{Autoavaliação e a ReFleXividade no CONTEXTO da PESQUISA AÇÃo- COLABORATIVA}

A inserção do professor no contexto da pesquisa ação-colaborativa, sobretudo em momentos em que se discorre no coletivo sobre as práticas educativas e avaliativas que cada um desenvolve na universidade, constitui-se um espaço de reflexão que cada um gera para si, compreendendo o modo como se avalia e se percebe na relação com o outro (os próprios pares e os estudantes) numa condição de poder autoavaliar-se e, disso, (re)significar suas práticas docentes na universidade. A partilha e a troca de experiências pedagógicas conduzem os participantes a criarem um ambiente que acolhe as singularidades de cada um e as potencializa na dimensão do coletivo, gerando, assim, novas singularidades que se efetivam nos novos modos operativos de ensinar e de avaliar, que cada uma faz no contexto do seu trabalho na universidade.

É o aprender com o outro, com a prática do outro, mas na intersecção com a sua própria prática, com o seu próprio modo de conceber a docência universitária como um espaço perene de formação e de construção de novas possibilidades do fazer docente. Nesta ótica, a coletividade provoca e promove reflexões que levam cada um a desenvolver em si um processo de autoavaliação que implica, no contexto da pesquisa, uma condição profissional de (re)construção de práticas educativas e avaliativas que emergem da necessidade e da viabilidade de desenvolver-se profissionalmente no contexto das dinâmicas cotidianas do fazer a docência universitária uma prática reflexiva, portanto inovadora.

Concebemos a autoavaliação como um elemento da ação humana essencial para a dinâmica cognitiva e interação social. Não poderia estar ausente da vida cotidiano dos indivíduos e de seu convívio social, logo no convívio social de docentes universitários, que pela pesquisa ação-colaborativa se inserem numa dinâmica de autoavaliar-se para fazerem o que Angélica também faz no seu contexto de atuação na universidade quando diz que sempre procuro refletir sobre a minha prática pedagógica e o que eu posso fazer para melhorar. A reflexão sobre a prática significa a autoavaliação de suas ações educativas que, em sendo analisadas pela própria professora, facultam uma reconfiguração das mesmas, uma reestruturação que viabilize melhoras, logo, que sejam construídas no ideário que a professora tem de si e de sua prática, como modo de favorecer aprendizagem aos estudantes. $\mathrm{O}$ resultado esperado é sempre aquele que revele uma prática que seja melhor que uma outra anteriormente desenvolvida, e que portanto gere aprendizagens aos estudantes.

Nossa compreensão da autoavaliação, que não é um instrumento de coleta de dados, mas uma dinâmica cognitiva que produz dados para assessorar ações no cotidiano humano, gera no contexto da pesquisa ação-colaborativa a condição de produção de ações que (re)significam nossas práticas. Daí a compreensão de que a pesquisa impacta nos modos operativos que a 
professora Angélica desenvolve para refletir sobre sua prática na docência em química, autoavaliando-se em sua trajetória numa perspectiva de mudar as práticas e torná-las mais próximas da perspectiva educacional que considera o ensino em razão da aprendizagem. Assim, em um de seus trechos narrativos, a professora relata que

sempre procuro refletir sobre a minha prática pedagógica e o que eu posso fazer para melhorar e aí eu concordo com o colega que a gente deve sempre ter o ensino focado na aprendizagem, por esse motivo eu vim pra cá, pra aprender com vocês aquilo que eu já venho fazendo há tempo, com uma forma de engenheira, porque eu acho que o engenheiro é técnico, e ver se eu consigo colocar isso num formato mais... digamos assim, pedagógico, me aproximar mais dessa área de educação. (Angélica, relato da roda de conversa 2017)

Acreditar que o ensino deve estar fundamentado na perspectiva de garantir que a aprendizagem aconteça é uma forma de produzir a autoavaliação de si e de sua prática, ao se reconhecer engenheira que está na docência universitária. A partir dessa condição, Angélica reforça a ideia de que está na pesquisa ação-colaborativa, por meio da qual tem a oportunidade de refletir a docência e aprender com a experiência do outro, é uma forma de gerar uma autoavaliação e poder continuar fazendo o que já faz a algum tempo, ou seja, ensinar Química na universidade. A diferença é que ao vir participar da pesquisa-ação colaborativa a professora considera que ela terá condições de trazer para o debate com os pares suas inquietações a respeito da prática docente que desenvolve na universidade. $\mathrm{O}$ formato pedagógico que ela deseja compreender nas experiências partilhadas pelo grupo é a porta de entrada para Angélica pensar as formas como tem feito o ensino em Química e de como esse ensino tem gerado aprendizagem nos estudantes. É do reconhecimento autoavaliativo que faz de si no contexto de sua atividade docente, que a docente pensa o lugar da reflexão e da troca de experiências entre ela e os demais professores participantes da pesquisa. Portanto, a concepção de autoavaliação que a professora desenvolve vai além da compreensão que alguns professores utilizam em sala de aula, para apenas gerar coleta de dados sobre o desempenho dos alunos ou ainda sobre seus próprios desempenhos na prática educativa.

O uso do que se chama autoavaliação no contexto da sala de aula cumpre, às vezes, apenas, a função de um instrumento de coleta, que tem sido usada de forma pontual e na maioria das vezes não acrescenta muito ao processo de aprendizagem. A ultrapassagem deste uso no processo de aprendizagem será possível quando se compreende o significado dos julgamentos de valor que o aluno e professor fazem do que está acontecendo não para a função somativa da avaliação, mas para a função formativa do processo de aprendizagem e ensino. Essa perspectiva sugere que a professora passa a ter a condição de promover modificações significativas que apontem que podem prosseguir ou trabalhar lacunas da aprendizagem.

Tomando a trajetória reflexiva que a professora tem feito no contexto da pesquisa ação colaborativa, é possível identificar momentos em que sua prática sinaliza um tratamento da 
autoavaliação como instrumento de coleta de dados que serve, tão somente, para que Angélica possa saber se os alunos estão ou não aprendendo Química. Disso ela passa a entender que a aprendizagem está diretamente relacionada com as práticas educativas que desenvolve, que precisam considerar, inclusive, as estratégias que desenvolve para promover as aulas e consequentemente as avaliações dos estudantes. Neste contexto, a autoavaliação deixa de ser uma mera condição de coleta de dados, com fim em si mesma, e passa a significar um processo de autoregulação que o professor faz de si mesmo, ao considerar que as práticas avaliativas envolvem processos mais complexos que demandam uma relação intrínseca entre ensino e aprendizagem.

Assim, compreendemos que em qualquer atividade de sala de aula para o estudante apreender as informações que estão sendo apresentadas, a autoavaliação vai agindo auxiliando a memória de trabalho, de curta e de longa duração, guiando a efetivação das aprendizagens. Por estas razões a autoavaliação deve ser compreendida e inserida no processo da avaliação formativa da prática pedagógica que se faz e refaz com o outro, que neste contexto é o discente. Instalar a fala do estudante permite que ele troque seus conhecimentos, suas dúvidas/questionamentos com o professor e colegas, essencial para emergir motivação e comprometimento de seu processo de aprendizagem. O aluno "se sente ouvido" e essa escuta promove melhoria do ensino e da aprendizagem. Guia o docente sobre o que pode ser melhor para o grupo. E essa ação deve ser balizada por uma perspectiva do docente de alinhar o pensamento e a ação de modo a estar atento aos caminhos que deve percorrer, logo, caminhos que possibilitem a aprendizagem do estudante. É uma ação que se faz e refaz na ação avaliativa de compreender como os sujeitos aprendem com a prática docente. Assim, avaliar implica tomar consciência e gerar um processo de autoavaliação, que é uma ação cotidiana do pensamento e da ação das ações de si mesmo.

Kenski, (1988, p. 131) explica que

o ato de avaliar na vida cotidiana se dá, permanente, pela unidade imediata de pensamento e ação. Nesta unidade a pessoa precisa estar sempre pronta para identificar o que é para si o 'verdadeiro', o 'correto', opções que vão lhe indicar o melhor caminho a seguir, o que fazer. Muitas vezes essa escolha não corresponde a um conhecimento aprofundado, real, daquilo a que se refere a opção.

O processo avaliativo que o indivíduo realiza em todos os momentos do seu cotidiano se faz com base em juízos provisórios, são opiniões que transitam dos seus relacionamentos consigo e com outros, permitem tomadas de decisões essenciais para cada momento. Isto não acontece dissociado da sua capacidade intelectual, seus sentidos, sentimentos, habilidades, ideologias e ideias. São os relacionamentos sociais e sua postura pessoal. "O dia a dia da sala de aula não se separa da cotidianidade de cada um dos indivíduos que aí se relacionam" (KENSKI, 1988, p. 132). Isto significa que professores e alunos avaliam a todo o momento a todos e a tudo. Necessariamente são essas ações que guiam tomadas de decisões, estabelecem relacionamentos individuais e grupais. $\mathrm{O}$ contexto da sala de aula é um dos palcos dessas

\begin{tabular}{|l|c|c|c|c|c|}
\hline C Rev. Inter. Educ. Sup. & Campinas, SP & v.4 & n.3 & p.664-684 & set./dez. 2018 \\
\hline
\end{tabular}


ações. E vale ressaltar que nas relações de sala de aula acontecem dois posicionamentos básicos nem sempre convergentes: o do professor e o aluno. “... juízos, positivos ou negativos, podem recair em atitudes diferenciadas e que se limitam, em termos extremos, em uma atitude de atenção permanente às mudanças ocorridas no comportamento da pessoa que está sendo avaliada" (KENSKI, 1988, p. 134). Observa-se na colaboração e participação positiva até todos ao atos de resistência e oposição.

O docente emite juízos que vão guiar a forma de seu relacionamento com os alunos, desde prêmios, castigos, elogios depende de como as ações estejam condizentes com as expectativas para o processo de ensino e aprendizagem. Algumas decisões são tomadas nas expectativas frustradas ou assertivas. (KENSKI, 1988).

A prática avaliativa vai se efetivando durante o processo de interação em sala de aula na dinâmica da autoavaliação. Vão emergindo decisões que estão diretamente ligadas ao conteúdo, produção do conhecimento pelo aluno, entre outras causas. Nessas relações entre professor e aluno a aprendizagem vai se processando alcançando ou não a aprendizagem desejada. Quando isto acontece com um docente que tem clareza teórica do que está acontecendo ele vai tomando as decisões no processo ensino e aprendizagem vivenciando a prática da teoria.

Quando esta dinâmica que implica construção de conhecimento tem a participação consciente e crítica dos alunos observa-se que eles constroem sentido no que aprendem. O professor muda de lugar de ser o único avaliador de tudo que ele e alunos vivenciam para se integrarem no que chama-se avaliação formativa que pode promover autorregulação do ensino e aprendizagem. Todos são parceiros do processo de aprendizagem, de ensino e necessariamente de avaliação. O foco é complexo e centra-se no grau e dificuldade de aprendizagem emergido no processo de autoavaliação de todos, forma como o conhecimento é ensinado e aprendido, as estratégias de aprendizagem e suas as tarefas acadêmicas, os recursos utilizados, a clareza dos objetivos guiando as ações de cada um. O resultado é que o grupo vai se reorganizando de acordo com as necessidades identificadas por todo o grupo.

A autoavaliação pode ser a mola mestra para mudanças efetivas e significativas e a construção de um ensino inovador que transforma relações, valoriza a dinâmica das aprendizagens implícitas e explícitas, permite o desenvolvimento da capacidade crítica do que lhe é interno e externo.

A autoavaliação vai além das respostas que os alunos em relatórios estruturados informando sua opinião do que acontece nas aulas. É compreendida como uma reflexão mais profunda, o encontro do indivíduo com o objeto de conhecimento num processo de análise identificando as alterações ocorridas durante os relacionamentos, o aluno se coloca como sujeito da sua aprendizagem e o professor como sujeito de sua docência.

\begin{tabular}{l|l|l|l|l|l} 
(C) Rev. Inter. Educ. Sup. & Campinas, SP & v.4 & n.3 & p.664-684 & set./dez. 2018
\end{tabular}


Para o docente esse momento de reflexão profunda da sua realidade permite emergir seus desejos, seus objetivos, seus sucessos, suas verdades, seu conhecimento. São momentos de desorganização e reorganização dos pensamentos e ações. Se estiverem no nível da consciência crítica têm força para reorientar ou não a direção da aprendizagem e do ensino. É "um processo crítico de ensino visando uma educação transformadora, a ênfase da avaliação vai estar nas relações efetuadas no contato diário com o conhecimento" (KENSKI, 1988, p. 141).

\section{CONSIDERAÇÕES}

A docente Angélica expressa o medo que tem em mudar, em flexibilizar, em "perder o caminho." De fato, a mudança torna-se muito difícil, tanto para estudantes, quanto para os docentes. Formados num paradigma em que a professora dita as regras, dá a nota, reprova, exige que os estudantes repitam aquele conteúdo que teria sido "passado", torna-se muito difícil mudar as representações e, consequentemente, as atitudes. Na concepção de Pozo (2009, p. 200), as representações dos professores, embora muitos não tenham consciência, orientam as suas práticas: "Sem dúvidas há outras que não temos consciência e que não obstante influem no que fazemos: as teorias implícitas."

Todavia, nossa experiência na pesquisa-ação colaborativa tem nos permitido perceber que as práticas docentes são (re)significadas quando os professores as narram, e delas fazem emergir o contexto do seu trabalho educativo no cotidiano da sala de aula. Logo, o contexto se apresenta não como um pano de fundo, apenas, das ações educativas, mas como elemento de problematização da prática, que é tencionada pelos diferentes modos do professor desenvolver a sua docência e de, consequentemente, avaliá-la a luz de novos paradigmas, que surgem como mecanismos mobilizadores de mudança da própria prática. É esse o momento e função da autoavaliação. Momento em que a professora Angélica desenvolve reflexões sobre seus modos de fazer e de avaliar os estudantes no ensino de Química, criando uma condição dialógica com os pares, bem como com outros autores e atores da docência em Química, como uma forma de modificar e buscar novos resultados para o processo avaliativo que tem desenvolvido em suas atividades docente.

Há um momento em que a crise paradigmática do trabalho avaliativo surge como elemento problematizador da prática docente, que é tecida e refletida no coletivo. Mas é da crise e do reconhecimento desta, que a professora Angélica passa a querer compreender novos modos de fazer a docência no contexto das práticas educativas de ensino de Química, para as quais a problematização surge no paradigma da aprendizagem e do modo como a avaliamos. Essa crise paradigmática começa a ser desvelada e a criatividade da professora Angélica começa a inserir uma nova concepção de aprendizagem e como avalia-la que transcende a noção de checagem avaliativa. $\mathrm{O}$ diálogo com os pares, a reflexão em grupo e a troca de experiências lhe permite (re)configurar sua prática educativa e avaliativa. Neste contexto, vemos uma

\begin{tabular}{l|l|l|l|l|l}
\hline () Rev. Inter. Educ. Sup. & Campinas, SP & v.4 & n.3 & p.664-684 & set./dez. 2018 \\
\hline
\end{tabular}


modificação dos paradigmas de aprendizagem e sua avaliação, por meio do qual esta docente e os demais colegas passam a desenvolver novas concepções e perspectivas sobre o ato de avaliar na universidade. Afinal, como a própria Angélica expressa, a avaliação é um processo, "é a bola girando na roda".

Assim, o estudo evidenciou a importância do processo autoavaliativo no contexto da função formativa da avaliação que se apresenta como um espaço de reflexão que o docente desenvolve em busca de compreender e efetivar os melhores caminhos avaliativos de que lança mão em sua prática educativa. A participação da docente na pesquisa-ação colaborativa possibilitou a ela uma aproximação e consequente conhecimento com as práticas educativas de outros docentes participantes, dando a ela a oportunidade de socializar, analisar e perceber o modo como ela faz a avaliação em Química e como esse modo ainda estava arraigado numa concepção tradicional de aprendizagem que considera muito mais a verificação classificatória para dar nota, do que o processo e sua natureza.

Estar num grupo que discute suas práticas avaliativas, busca perceber as implicações de suas avaliações no processo de aprendizagem dos estudantes, estar aberta aos diálogos com os pares e a realizar estudos sobre a temática fez com que a professora Angélica se inserisse num movimento formativo oportunizado pela pesquisa ação-colaborativa, vista como um espaço de formação dialógico, no qual a aprendizagem se faz com a participação efetiva do outro, sobretudo pela observação e análise da própria prática.

\section{REFERÊNCIAS}

ALMEIDA, Lucile Ruth de Menezes. Avaliação da aprendizagem: reflexões sobre os desafios atuais. In: RIBEIRO, Marinalva Lopes; MARTINS, Édiva de Souza; CRUZ, Antonio Roberto Seixas. (Org.) Docência no ensino superior: desafios da prática educativa. Salvador: EDUBA, 2011.

ALMEIDA, Lucile Ruth de Menezes. Avaliação formativa no contexto da construção do mapa conceitual. Sitientibus: Revista da Universidade Estadual de Feira de Santana,. ano I, n. 1, jul./dez. 1982.

BEHRENS, Marilda Aparecida. O paradigma emergente e a prática pedagógica. 3 ed., Curitiba: Champagnat, 2003.

CARPIM, Lucymara; BEHRENS, Marilda Aparecida; TORRES, Patrícia Lupion. Paradigma da complexidade na prática pedagógica do professor de educação professional no século 21 .

B. Tec. Senac, Rio de Janeiro, v. 40, n.1, p. 90-107, jan./abr. 2014.

GRILLO, Marlene Correro LIMA; Valderez M. do R. O fazer pedagógico e as concepções de conhecimento. In: FREITAS, Ana Lúcia Souza de S.; GESSINGER, Rosana M.; GRILLO, Marlene; LIMA, Valderez M. do R. (Org.). A gestão da aula universitária na 
PUCRS / Porto Alegre: EDIPUCRS, 2008.

HADJI, Charles. Avaliação desmistificada. Porto Alegre: Artmed Editora, 2001.

KENSKI, Vani Moreira. In: VEIGA, Ilma Passos Alencastro (Org.). Repensando a didática. SP: Papirus, 1988.

LUCKESI, Cipriano Carlos. Avaliação da aprendizagem escolar: estudos e proposições. 2 ed. SP: Cortez, 1995.

LUCKESI, Cirpiano Carlos. O que é mesmo o ato de avaliar a aprendizagem? Disponível em Pátio. Porto Alegre: ARTMED. Ano 3, n. 12, fev./abr. 2000. Disponível em:

<https://www.nescon.medicina.ufmg.br/biblioteca/imagem/2511.pdf〉. Acesso: 26 dez. 2017.

MORAES, Maria Cândida. O paradigma educacional emergente. Campinas, SP: Papirus, 1997.

MORIN, Edgar. La epistemología de la complejidad. Gazeta de Antropología, n. 20, 2004. Disponível em: 〈http://www.ugr.es/ pwlac/G20_02Edgar_Morin.html>. Acesso em $26 \mathrm{dez}$. 2017

PERRENOUD, Phillippe. Avaliação: da excelência à regulação das aprendizagens - entre duas lógicas. Porto Alegre, RS: Artes Médicas Sul, 1999.

PIMENTA, Selma Garrido. Pesquisa-ação crítico-colaborativa: construindo seu significado a partir de experiências com a formação docente. Educação e Pesquisa, São Paulo, v. 31, n. 3, p. 521-539, set./dez. 2005.

POZO, Juan Ignácio. Aprendizes e mestres: a nova cultura da aprendizagem. Porto Alegre: Artmed, 2002.

POZO, Juan I.; ECHEVERRÍA, M. del Puy Pérez. (Coord.). Psicologia del aprendizaje universitario: La formación en competencias. Madrid: Morata, 2009.

RIBEIRO, Marinalva Lopes.; MUSSI, Amali de Almeida. Inovação da prática pedagógica de professores do ensino universitário pela pesquisa-ação colaborativa. UEFS, Resolução CONSEPE 011/2015.

SANMARATÍ, Neus. Avaliar para aprender. Porto Alegre: Artmed, 2009.

ZABALA, Antoni. A prática educativa: como ensinar. Porto Alegre: ArtMed, 1998. 


\section{Sobre os Autores}

${ }^{1}$ Fabrício Oliveira da Silva

E-mail: faolis@ig.com.br - ORCID: Universidade do Estado da Bahia - Brasil

Doutor em Educação pela Universidade do Estado da Bahia (UNEB)

\section{${ }^{2}$ Marinalva Lopes Ribeiro}

E-mail: marinalva_biodanza@ hotmail.com - ORCID:

Universidade Estadual de Feira de Santana - Brasl

Doutora em Educação pela Université de Sherbrooke (Canadá). Pós-Doutorado em Educação pela

Universidade do Vale do Rio dos Sinos (UNISINOS)

\section{${ }^{3}$ Lucile Ruth de Menezes Almeida}

E-mail: lucile_ruth@bol.com.br - ORCID:

Universidade Estadual de Feira de Santana - Brasil

Mestrado em Mestrado em Música e Educação. Southwestern Baptist Theological Seminary. 